\title{
Analysis of strong ground motions and site effects at Kantipath, Kathmandu, from 2015 Mw 7.8 Gorkha, Nepal, earthquake and its aftershocks
}

\author{
Yadab P. Dhakal', Hisahiko Kubo, Wataru Suzuki, Takashi Kunugi, Shin Aoi and Hiroyuki Fujiwara
}

\begin{abstract}
Strong ground motions from the 2015 Mw 7.8 Gorkha, Nepal, earthquake and its eight aftershocks recorded by a strong-motion seismograph at Kantipath (KATNP), Kathmandu, were analyzed to assess the ground-motion characteristics and site effects at this location. Remarkably large elastic pseudo-velocity responses exceeding $300 \mathrm{~cm} / \mathrm{s}$ at $5 \%$ critical damping were calculated for the horizontal components of the mainshock recordings at peak periods of 4-5 s. Conversely, the short-period ground motions of the mainshock were relatively weak despite the proximity of the site to the source fault. The horizontal components of all large-magnitude ( $M w \geq 6.3)$ aftershock recordings showed peak pseudo-velocity responses at periods of 3-4 s. Ground-motion prediction equations (GMPEs) describing the Nepal Himalaya region have not yet been developed. A comparison of the observational data with GMPEs for Japan showed that with the exception of the peak ground acceleration (PGA) of the mainshock, the observed PGAs and peak ground velocities at the KATNP site are generally well described by the GMPEs for crustal and plate interface events. A comparison of the horizontal-to-vertical (H/V) spectral ratios for the S-waves of the mainshock and aftershock recordings suggested that the KATNP site experienced a considerable nonlinear site response, which resulted in the reduced amplitudes of short-period ground motions. The GMPEs were found to underestimate the response values at the peak periods (approximately 4-5 s) of the large-magnitude events. The deep subsurface velocity model of the Kathmandu basin has not been well investigated. Therefore, a one-dimensional velocity model was constructed for the deep sediments beneath the recording station based on an analysis of the $H / V$ spectral ratios for S-wave coda from aftershock recordings, and it was revealed that the basin sediments strongly amplified the long-period components of the ground motions of the mainshock and large-magnitude aftershocks.
\end{abstract}

Keywords: Gorkha earthquake, Kathmandu basin, Site effects, Long-period ground motion

\section{Background}

The $2015 \mathrm{Mw} 7.8$ Gorkha, Nepal, earthquake occurred at 11:56 local time (UTC + 05:45) on April 25, and several moderate- to large-magnitude aftershocks followed the event. The mainshock caused the widespread damage of buildings and resulted in the loss of more than 8600 human lives in cities and villages; approximately $20 \%$ of the casualties were from various sites located in the

*Correspondence: ydhakal@bosai.go.jp

National Research Institute for Earth Science and Disaster Prevention, Tsukuba, Japan
Kathmandu basin (Ministry of Home Affairs, Government of Nepal 2015). In addition, a major aftershock of Mw 7.3 on May 12 resulted in over 200 casualties and additional building damage, mostly in the epicentral area. A nationwide permanent monitoring network of strong ground-motion stations does not yet exist in Nepal (as of January 2016). Strong ground motions recorded at Kantipath (KATNP), Kathmandu (see Fig. 1 for location), by the United States Geological Survey (USGS) NetQuakes strong-motion sensor have been made available to the community through the Center for Engineering StrongMotion Data (CESMD 2015). The seismograph at the 


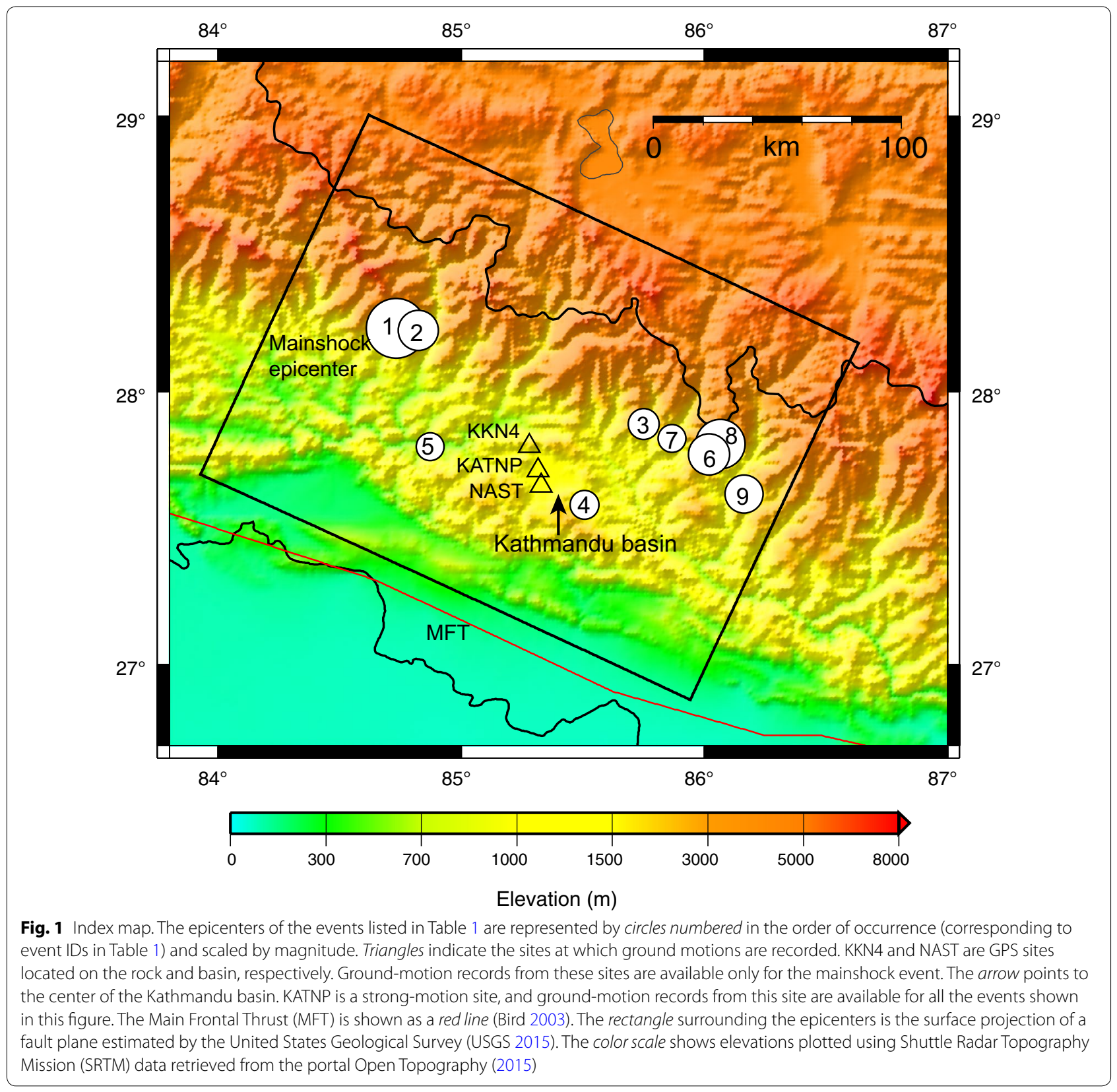

KATNP site was installed inside a one-story reinforced concrete building (Dixit et al. 2015). By October 2015, recordings from nine events (the mainshock and its eight major aftershocks) could be retrieved from the CESMD. The origin time and the locations and magnitudes of the events reviewed by USGS are listed in Table 1, and the epicentral locations of the events are depicted in Fig. 1. The magnitudes of the events range from $\mathrm{Mw} 5.0$ to 7.8, and their epicentral distances range from approximately 23 to $84 \mathrm{~km}$. All of these events were shallow-focus events with focal depths of $10-23 \mathrm{~km}$ that occurred on low-angle reverse faults with dips in the north-northeast direction, with the exception of an Mw 5.1 event (Event 5 in Table 1), which was a normal-faulting event (USGS Event Page 2015).

In this study, we used the recordings from the KATNP site for the nine events listed in Table 1 . We also used ground-motion data (Galetzka et al. 2015) from two global positioning system (GPS) stations, KKN4 and NAST (shown in Fig. 1), for the mainshock. The KKN4 GPS station is located outside the Kathmandu basin at a hard rock site, whereas the NAST GPS and KATNP 
Table 1 Event locations and magnitudes from USGS

\begin{tabular}{lllllll}
\hline ID & Local origin time & Latitude & Longitude & Depth $(\mathbf{k m})$ & Magnitude & Magnitude type \\
\hline 1 & April 25, 2015, 11:56 & 28.2305 & 84.7314 & 8.22 & 7.8 & Mww \\
2 & April 25, 2015, 12:30 & 28.2244 & 84.8216 & 10 & 6.6 & $\mathrm{Mww}$ \\
3 & April 25, 2015, 12:41 & 27.8822 & 85.7505 & 10 & 5.5 & $\mathrm{mb}$ \\
4 & April 25, 2015, 14:40 & 27.5866 & 85.5058 & 10 & 5.3 & $\mathrm{mb}$ \\
5 & April 26, 2015, 05:01 & 27.7993 & 84.8715 & 13.61 & 5.1 & $\mathrm{Mww}$ \\
6 & April 26, 2015,12:54 & 27.7711 & 86.0173 & 22.91 & 6.7 & $\mathrm{Mww}$ \\
7 & April 26, 2015,22:11 & 27.8297 & 85.865 & 14 & 5.0 & $\mathrm{Mwb}$ \\
8 & May 12, 2015, 12:50 & 27.8087 & 86.0655 & 15 & 7.3 & $\mathrm{Mww}$ \\
9 & May 12, 2015, 13:21 & 27.625 & 86.1617 & 15 & 6.3 & $\mathrm{Mww}$ \\
\hline
\end{tabular}

strong-motion stations are located in the basin. Several papers (e.g., Bhattarai et al. 2015; Dixit et al. 2015; Takai et al. 2016) already discussed the main features of the ground-motion recordings at the KATNP site for the mainshock. This paper differs from the previous papers in that we analyzed the strong-motion data at the KATNP site for a greater number of events and compared the observed ground-motion parameters of these events with those calculated using ground-motion prediction equations (GMPEs) for Japan. This paper discusses the degree of nonlinearity during the mainshock in some detail. Additionally, a one-dimensional (1D) velocity model for deep sediments was constructed, and this paper describes the long-period site amplification effect with reference to this newly constructed velocity model.

\section{Ground-motion characteristics}

We uniformly processed all the recordings used in this study, applying a low-cut filter at $0.1 \mathrm{~Hz}$ to remove the long-period noises in the recordings. The filtered acceleration seismograms were integrated to obtain velocity seismograms. The north-south (NS), east-west (EW), and up-down (UD) components of the processed acceleration seismograms and normalized velocity seismograms for all events are shown in Fig. 2. Each component of the velocity seismograms was normalized by the maximum amplitude achieved in any of the three components for each event to ensure that the relative strengths of the later phases are observable in the figure. The velocity seismograms for aftershock events of $\mathrm{Mw} \geq 6.3$ clearly demonstrate that significant ground motions continued for an extended duration. This is not evident in the seismograms for the mainshock because the direct arrivals had very large amplitudes at periods slightly larger than the site resonance period of approximately $4 \mathrm{~s}$ (see the next section) as a result of the strong pulse-like input ground motions with periods of 6-7 $\mathrm{s}$ at the base of the sediments (e.g., Galetzka et al. 2015; Takai et al. 2016). A comparison of the waveforms at two different passbands (see Additional file 1) clearly demonstrated that strong later phases with periods of 3-4 s dominated the ground motions during the mainshock.

Nepal and the Himalayan regions in general have not obtained the number of strong-motion recordings necessary for seismic hazard analysis because of the sparse and underdeveloped strong-motion monitoring network in the region (Parajuli et al. 2008; Nath and Thingbaijam 2011). The first country-wide seismic hazard analysis project in Nepal (HMG and UNDP/UNCHS 1994) adopted the GMPE developed for Japan by Kawashima et al. (1984), mainly because this GMPE employed data from plate interface thrust events and the sites were sufficiently similar to be applicable to Nepal. During a comprehensive earthquake disaster mitigation study in the Kathmandu Valley (JICA and MoHA 2002), the GMPE developed by Boore et al. (1997) for western North American earthquakes was used, mainly because this GMPE accurately described the derived ground-motion data for the Ms 6.6 Udayapur earthquake that occurred in the eastern part of Nepal. It should be noted that the Udayapur earthquake was a relatively deep event with a focal depth of $57 \mathrm{~km}$ (Dixit 1991) and that it was different from plate interface events (Ghimire and Kasahara 2007). Parajuli et al. (2008) selected the GMPE developed for subduction zone events by Atkinson and Boore (2003) for use in probabilistic seismic hazard analysis in Nepal without further explanation regarding this choice. Goda et al. (2015) adopted the GMPE by Kanno et al. (2006) to assess the ground motions of the mainshock in Nepal on the grounds that this GMPE was found to be superior to other applicable GMPEs regarding its ability to predict peak ground accelerations (PGAs) at rock sites in North India and Nepal in an extensive analysis of worldwide GMPEs by Nath and Thingbaijam (2011). Goda et al. (2015) also selected the GMPE by Kanno et al. (2006) because of its applicable magnitude ranges and suitable distance definition for large-magnitude events. 


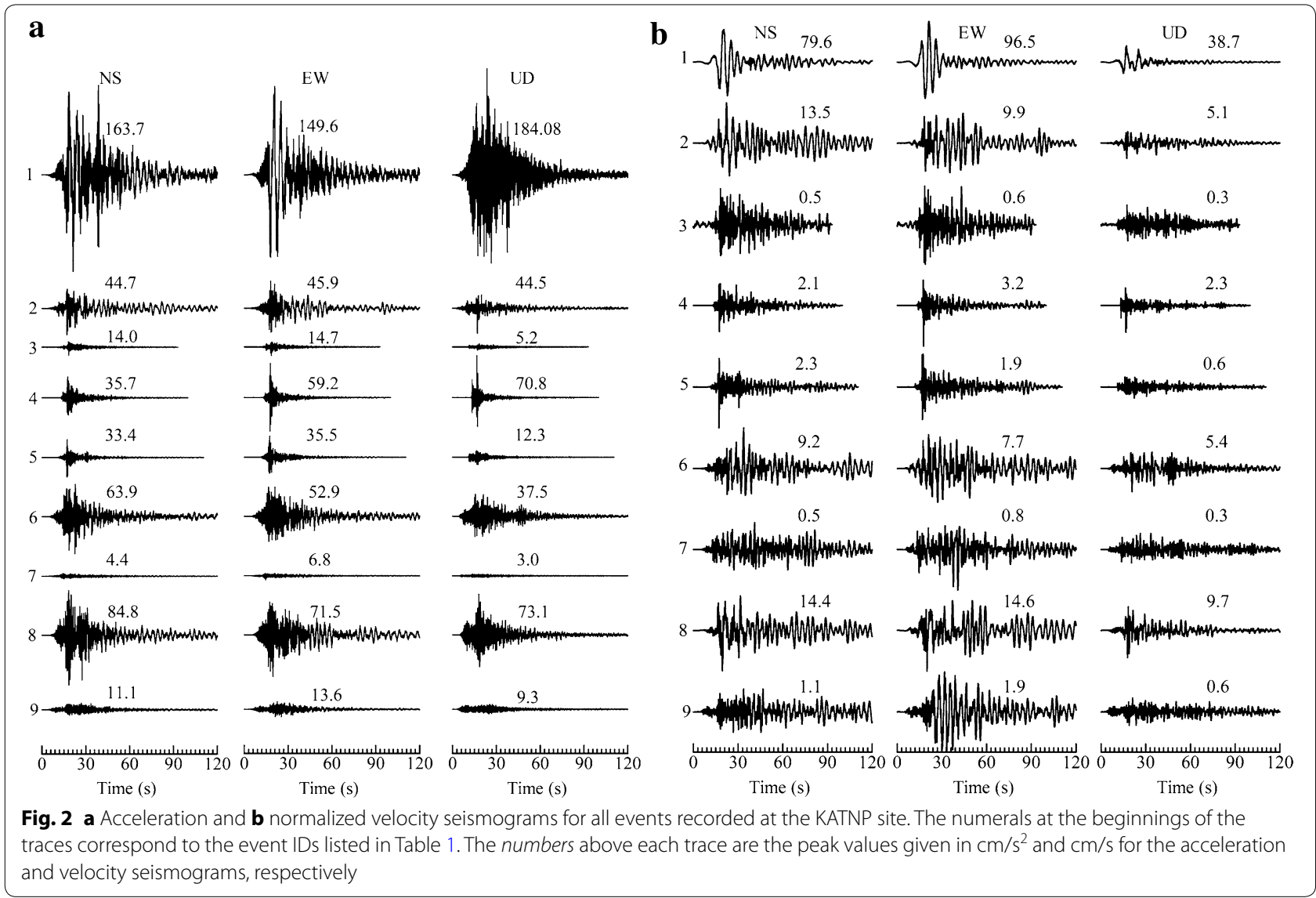

Based on the above discussion and because the Gorkha earthquake and its major aftershocks occurred along the Main Himalayan Thrust (MHT), which is a megathrust plate interface (Avouac et al. 2015), it is reasonable to employ GMPEs developed for events that occurred along other megathrust plate interfaces, such as in Japan, to assess the ground-motion parameters for the Nepal earthquakes. However, in the Himalayan region, the plates that are separated by the thrust interface are continental in nature and do not resemble typical thrust interfaces in subduction zones where an oceanic plate subducts beneath a continental plate. Morikawa and Fujiwara (2013) updated the database used by Kanno et al. (2006) with additional data and obtained a GMPE applicable to different tectonic environments as well as sites located on deep sediments. Therefore, this paper compares the ground-motion parameters, namely the PGAs, peak ground velocities (PGVs), and response spectra, observed at the KATNP site with those obtained from the GMPE developed by Morikawa and Fujiwara (2013) for Japan for both plate interface and crustal events. To elucidate the epistemic uncertainties associated with the GMPEs, the observed PGAs and PGVs were also compared with those obtained from the GMPEs developed by Si and Midorikawa (1999), which have been used by the Headquarters for Earthquake Research Promotion of Japan to create national seismic hazard maps for Japan.

The vector sum (the square root of the sum of the squares) of the two horizontal components of the acceleration seismograms was calculated at each time step, and the maximum vector sum among all of the time steps was defined as the observed PGA at each site. This PGA was then compared with the PGA from the GMPE by Morikawa and Fujiwara (2013). The PGV at each site was obtained in a similar manner. Figure 3 compares the PGAs and PGVs observed at the KATNP site with those obtained from the GMPEs for the six largest events listed in Table 1. The prediction curves for the GMPEs by Morikawa and Fujiwara (2013) were obtained under the assumption that the depth of the layer at which the $\mathrm{S}$-wave velocity is $1.4 \mathrm{~km} / \mathrm{s}$ is $500 \mathrm{~m}$ beneath the site and that the average S-wave velocity in the upper $30 \mathrm{~m}$ of the soil profile (AVS30) is $200 \mathrm{~m} / \mathrm{s}$. These values were adopted based on the previous studies (Pandey 2000; JICA and MoHA 2002). The equations by Si and Midorikawa (1999) for the PGA and PGV are applicable to soft and stiff soil site conditions, respectively. A stiff soil site is defined as having an AVS30 of approximately 


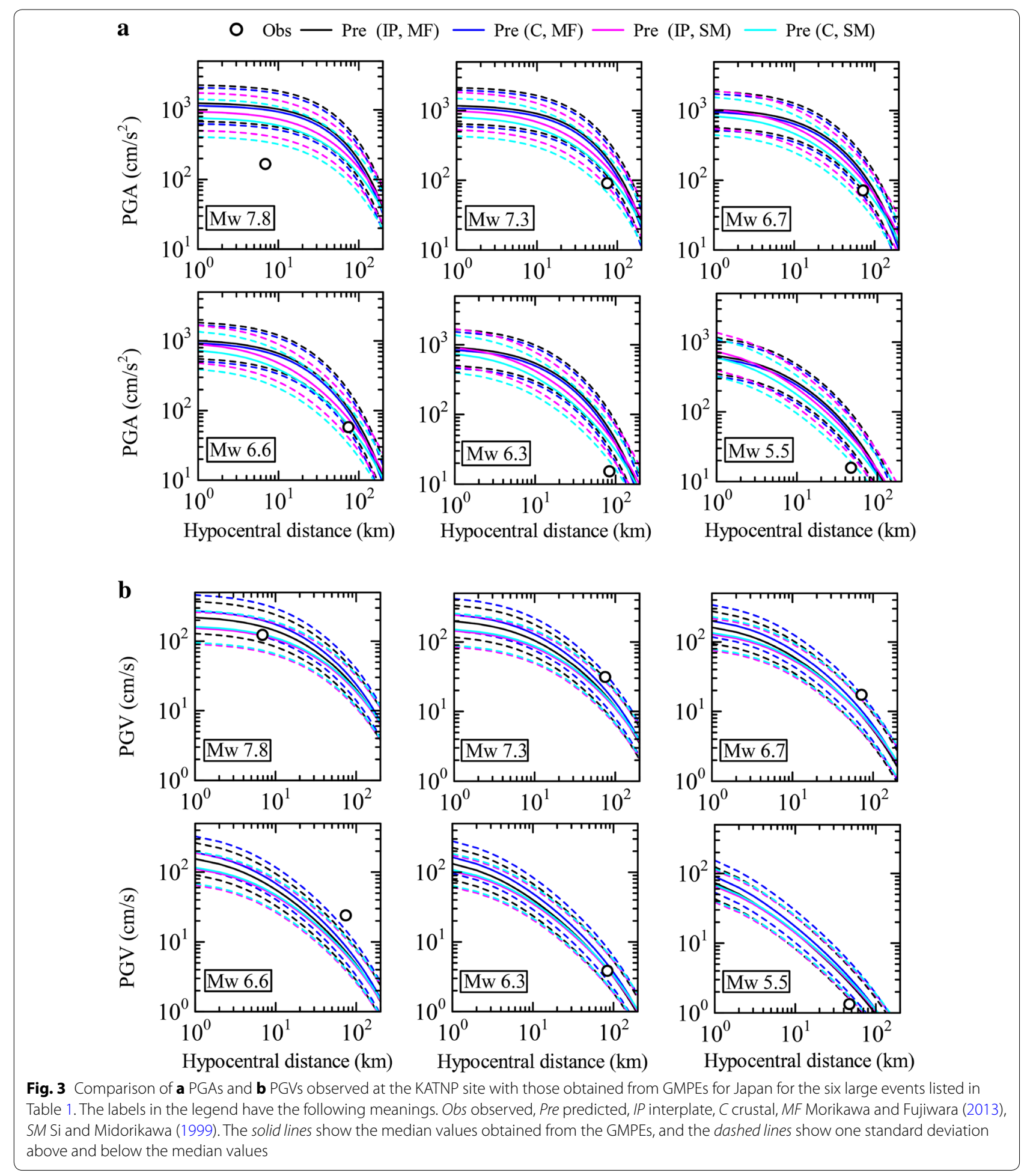

$600 \mathrm{~m} / \mathrm{s}$. The predicted PGVs were corrected for the amplification effects due to the lower AVS30 at the KATNP site using the equations provided in $\mathrm{Si}$ and Midorikawa (1999, 2000). Figure 3 clearly shows that with the exception of the PGA of the mainshock, the observed PGAs and PGVs are generally well described by the GMPEs for Japan and were generally within the standard error range. 
Figure 4 compares the observed elastic pseudo-velocity response spectra (PSVRS) at $5 \%$ critical damping with those obtained from the GMPEs by Morikawa and Fujiwara (2013) for the same events as shown in Fig. 3 assuming the site conditions described above. The observed PSVRS showed the following three features in comparison with those obtained from the GMPEs. First, the GMPEs tended to overestimate the observed PSVRS at periods shorter than approximately $0.3 \mathrm{~s}$; the spectra for the mainshock were systematically smaller at periods shorter than approximately $2 \mathrm{~s}$. This difference between the observed and calculated mainshock PSVRS may be partially attributable to the nonlinear site response discussed in the next section. Second, the observed spectra were well described by the GMPEs at intermediate periods (approximately 0.3-2 s) for aftershock events of $\mathrm{Mw} \geq 6.3$. Third, the GMPEs underestimated the observed spectra at periods of approximately $4 \mathrm{~s}$ for large events. The GMPEs tended to predict large PSVRS at periods shorter than the peak response periods of the observed data. The large observed response spectra at the peak periods may be partially explained by the large amplification effects of the basin sediments discussed in the next section. Whereas the basin sediments in Japan extend to depths of approximately $2-4 \mathrm{~km}$ above the hard rocks in large basin areas (J-SHIS 2016), the thickness of unconsolidated sediments in the Kathmandu basin is less than approximately $500 \mathrm{~m}$. This suggests that appropriate deep soil correction factors for the Kathmandu basin must be developed.

Figure 4 also shows that the PSVRS for the Mw 6.6 event were larger than those for the Mw 6.7 event by a factor of approximately 1.8 at a peak period of approximately $3.5 \mathrm{~s}$ despite the fact that the source-to-site distances of the two events were similar (see Fig. 1 for the locations of the events). The focal depth of the Mw 6.6 event was $10 \mathrm{~km}$, whereas that of the Mw 6.7 event was approximately $23 \mathrm{~km}$ (Table 1 ). The difference between the focal depths of the two events may be one of the reasons for the difference in their response amplitudes because shallow events can excite stronger long-period ground motions. The difference between the peak response amplitudes of the two events may also indicate the dependence of the basin response on the azimuth of the incident wave field (e.g., Kagawa et al. 1992), as the waves impinged on the basin from opposite directions.

During the mainshock, mostly low-strength masonry buildings, such as those made of bricks and mud mortar and those constructed without reinforcement elements, collapsed or were severely damaged at several sites in the

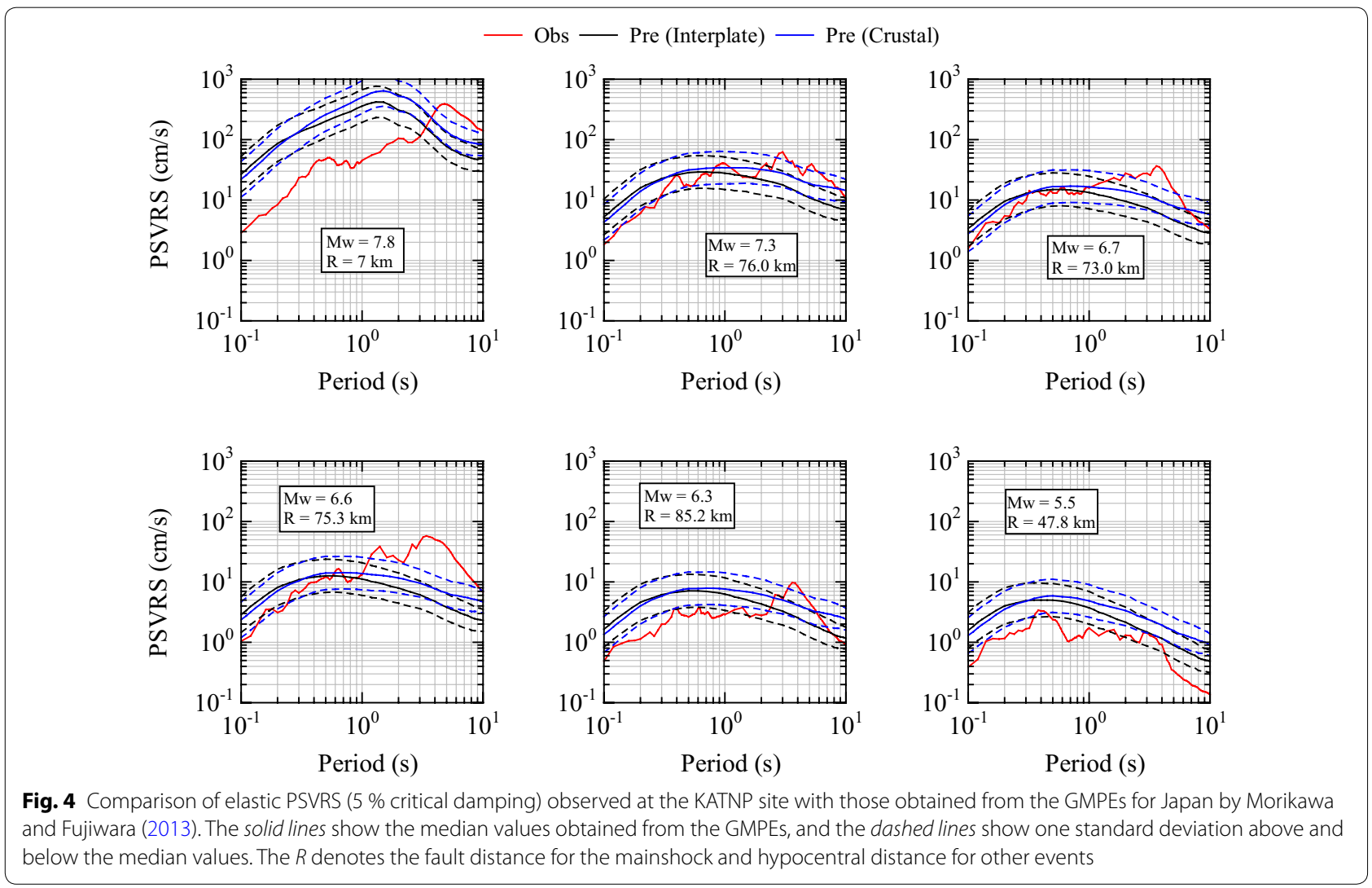


Kathmandu basin, whereas the reinforced concrete buildings in the area remained standing (Dhakal et al. 2015a, b; Galetzka et al. 2015; Goda et al. 2015; Hashash et al. 2015). The level of acceleration generally considered sufficient to produce ordinary damage to low-strength structures is approximately $0.1 \mathrm{~g}$ (Richter 1958). Hence, the selective damage of buildings during the mainshock may be attributable to the smaller PGAs and short-period ground motions in the Kathmandu basin. Here, it should be noted that in the northwestern portion of the Kathmandu basin several reinforced concrete buildings were damaged or collapsed (Goda et al. 2015; Hashash et al. 2015). Because of the lack of strong-motion recordings at the sites of damaged buildings, it is not clear whether the damage was due to large ground motions. An analysis of the design and construction of damaged buildings may reveal the intensity of the ground shakings in the area. Hashash et al. (2015) reported that some of the damage to the reinforced concrete buildings in the area may have been due to topographic and basin edge effects.

In spite of the proximity of the KATNP site to the source fault, the PGA of the mainshock was relatively small; this may be attributable to the earthquake rupture characteristics (e.g., Galetzka et al. 2015) and soil nonlinearity (e.g., Dixit et al. 2015). Several researchers' source inversion analyses (e.g., Kobayashi et al. 2015; Yagi and Okuwaki 2015) have shown that the Kathmandu basin is oriented in the direction of forward rupture directivity and is close to large-slip areas. Previous studies (e.g., Ide et al. 2011; Lay et al. 2012) of megathrust subduction zone events demonstrated that high-frequency seismic waves emanate from deeper areas of the rupture plane, in contrast to the large total slips that occurred at shallower parts of the rupture plane. The model of high-frequency radiation sources of the mainshock proposed by Yagi and Okuwaki (2015) shows that stronger high-frequency radiations occurred in deeper areas in the source fault rather than at the shortest fault distance from the
KATNP site. The indirect analysis of soil nonlinearity conducted in the present study demonstrated that the KATNP site indeed experienced a considerable nonlinear site response, as described in the next section. Thus, in summary, it may be inferred that the rupture characteristics and soil nonlinearity greatly contributed to the reduced PGAs and short-period ground motions, resulting in less damage and fewer casualties in the Kathmandu basin than expected (e.g., JICA and MoHA 2002).

Because of the growing number of mid- and high-rise apartment buildings in the Kathmandu basin, knowing the intensity of long-period ground motions would help with determining appropriate disaster mitigation measures. Table 2 lists the observed long-period groundmotion intensities as defined by the Japan Meteorological Agency (JMA) and those predicted using the GMPEs for absolute velocity response spectra (AVRS) proposed by Dhakal et al. (2015a, b). The observed intensities were calculated based on the peak AVRS from the period band of 1.6-7.8 s. Because Dhakal et al. (2015a, b) used the JMA displacement amplitude magnitude in their GMPEs, the Mw values listed in Table 1 have been converted to JMA magnitudes using the relationships between the two magnitudes given by Sato (1979) and Takemura (1990) for $\mathrm{Mw} \geq 7.3$ and $\mathrm{Mw}<7.3$, respectively. The observed longperiod intensity for the mainshock was 4 ; at this groundmotion intensity, people in the upper floors of buildings taller than approximately $60 \mathrm{~m}$ cannot remain standing without support, unsecured furniture moves a significant amount and may topple, and partition walls may crack (Nakamura 2013). Here, it should be noted that the AVRS predicted using the GMPEs by Dhakal et al. $(2015 \mathrm{a}, \mathrm{b})$ are much smaller than the observed AVRS at long periods. This is because the KATNP site is located a short distance from the fault, whereas the GMPEs by Dhakal et al. (2015a, b) employ the hypocentral distance, which is used for earthquake early warning at relatively large distances. However, the difference between the

Table 2 Long-period ground-motion intensities at the KATNP site

\begin{tabular}{|c|c|c|c|c|c|c|}
\hline ID & Magnitude & $\begin{array}{l}\text { Hypocentral } \\
\text { distance }(\mathbf{k m})\end{array}$ & $\begin{array}{l}\text { Observed long- } \\
\text { period intensity }\end{array}$ & $\begin{array}{l}\text { Predicted long- } \\
\text { period intensity }\end{array}$ & $\begin{array}{l}\text { Observed peak absolute } \\
\text { velocity response }(\mathrm{cm} / \mathrm{s})\end{array}$ & $\begin{array}{l}\text { Median predicted absolute } \\
\text { velocity response }(\mathrm{cm} / \mathrm{s})\end{array}$ \\
\hline 1 & 7.8 & 81.62 & 4 & 3 & 394.4 & 88.3 \\
\hline 2 & 6.6 & 75.34 & 3 & 2 & 55.7 & 34.1 \\
\hline 3 & 5.5 & 47.78 & 0 & 1 & 1.7 & 5.4 \\
\hline 4 & 5.3 & 25.35 & 0 & 1 & 2.9 & 6.9 \\
\hline 5 & 5.1 & 46.82 & 0 & 0 & 3.6 & 2.3 \\
\hline 6 & 6.7 & 72.98 & 2 & 2 & 36.8 & 43.8 \\
\hline 7 & 5.0 & 57.31 & 0 & 0 & 2.9 & 1.5 \\
\hline 8 & 7.3 & 76.02 & 3 & 2 & 62.6 & 41.5 \\
\hline 9 & 6.3 & 85.18 & 1 & 2 & 9.7 & 15.5 \\
\hline
\end{tabular}


observed and predicted long-period intensities is only 1 . During the mainshock, none of the mid-rise buildings in Kathmandu collapsed, but several buildings suffered significant nonstructural damage, and a few suffered severe structural damage (Goda et al. 2015; Hashash et al. 2015). The limited damage to the mid-rise buildings may be attributable to the short resonance period $(<2 \mathrm{~s})$ of the buildings in comparison with the predominant periods (approximately 4-5 s) of the ground motions during the mainshock.

\section{Local site condition and site characteristics}

The Kathmandu basin extends approximately 30 and $25 \mathrm{~km}$ in the east-west and north-south directions, respectively. Moribayashi and Maruo (1980) conducted the first gravity survey of the Kathmandu basin and estimated the depth to basement rocks to be approximately $650 \mathrm{~m}$ from the surface at the center of the basin. They also outlined the basement topography, which gradually becomes shallower toward the basin margins with the exposure of basement rocks at a few sites inside the basin, suggesting a complicated basement topography. Piya (2004) compiled a comprehensive subsurface geological database of the Kathmandu basin and reported the depths to basement rocks at 36 different sites. The depths to basement rocks were found to be in the range of $48-549 \mathrm{~m}$ from the surface. The site with the maximum depth (Bhrikutimandap) is located near the center of the city of Kathmandu and within approximately $2 \mathrm{~km}$ from the KATNP recording station. Core drilling at Kantipath reached $300 \mathrm{~m}$ below the surface but did not reach the basement (Sakai 2001). Two deep geological layers (an upper layer of lacustrine sediments and a lower layer of fluviatile granular sediments) of Pleistocene to Late Pliocene age have been generally recognized in the central area of the Kathmandu basin that overlies the Paleozoic basement metasediments (e.g., Yoshida and Igarashi 1984; Sakai 2001). Although several geological boreholes have been made in the Kathmandu basin (e.g., Piya 2004) and a general outline of its basement topography has been obtained (Moribayashi and Maruo 1980; Paudyal et al. 2013), an accurate and detailed seismic velocity model for the deep sediments of the Kathmandu basin has not yet been developed. Pandey (2000) reported $\mathrm{P}$-wave velocities of $1600-1650$ and $1850-1900 \mathrm{~m} / \mathrm{s}$ for the clayey and granular sediments, respectively, in the basin based on a common-depth-point reflection survey. Pandey (2000) also proposed a 1D S-wave velocity model, which is shown in Fig. 5c. The velocity model proposed by Pandey (2000) gives strong site amplifications at periods shorter than those observed at the KATNP site during the mainshock and large-magnitude aftershocks (see Figs. 4, 5e). Similar to the deep sediments, the seismic velocities of shallow soil layers, upon which most of the buildings in the area are founded, are little known. Borehole PS logging to a depth of $30 \mathrm{~m}$ was conducted at five sites in a central area of the Kathmandu basin by JICA and MoHA (2002) for seismic hazard mitigation planning. The borehole logs generally show that the upper $20 \mathrm{~m}$ of the soil column is mainly sand deposits, below which the clay deposits begin; the AVS30 ranges between 180 and $235 \mathrm{~m} / \mathrm{s}$ (JICA and MoHA 2002; Dhakal 2002).

To understand the site characteristics, such as the predominant period of the ground motion and the site amplification, the horizontal-to-vertical $(H / V)$ spectral ratios for the $\mathrm{S}$-waves and $\mathrm{S}$-wave coda were analyzed. The peak $H / V$ spectral ratio corresponds to the predominant period of the ground motion at which the input seismic motions are most strongly amplified (e.g., Lermo and Chavez-Garcia 1993). The $H / V$ spectral ratios for the $\mathrm{S}$-waves and S-wave coda are plotted in Fig. 5a, b, respectively. The $\mathrm{S}$-wave plot (Fig. 5a) shows that the spectral ratios at periods shorter than $0.5 \mathrm{~s}$ (i.e., frequencies lower than $2 \mathrm{~Hz}$ ) for the mainshock were systematically smaller than the mean spectral ratios for the aftershocks; furthermore, the predominant period of approximately $0.4 \mathrm{~s}$ for the aftershocks shifted to a period of approximately $0.7 \mathrm{~s}$ for the mainshock. The lower $H / V$ ratios for S-waves at short periods and the greater predominant period are characteristics of a nonlinear site response during strong shaking (e.g., Wen et al. 2006).

Noguchi and Sasatani $(2008,2011)$ introduced a quantitative index called the degree of nonlinearity (DNL), which is a measure of the area between the S-wave $H / V$ ratio curve for the mainshock and the curve of the mean $\mathrm{S}$-wave $H / V$ ratio for the small events. The area is zero when the site response is linear. However, considering the fluctuations in the calculated spectral ratios, Noguchi and Sasatani (2011) suggested that DNL values of at least 4 indicate nonlinearity. The DNL value for the data plotted in Fig. 5a is 9.7. This large DNL value and the reduction in the short-period $H / V$ ratios for the mainshock suggest that the KATNP site suffered a substantial nonlinear site response during the mainshock. Conversely, the $H / V$ ratios for the $\mathrm{S}$-waves for the mainshock at periods longer than $0.8 \mathrm{~s}$ do not show any systematic trend compared to the scattering of the spectral ratios for aftershocks from the mean spectral ratios. This suggests that the ground motions at longer periods were not affected by the nonlinearity. Previous studies (e.g., Aguirre and Irikura 1997) have reported that verticalcomponent ground motions are negligibly affected by site response nonlinearity in comparison with horizontalcomponent motions. These findings are supported by the richer short-period ground motions and larger PGA of the vertical component in comparison with those of the 




horizontal components during the mainshock (see the acceleration recordings in Fig. 2 for the mainshock).

Figure $5 \mathrm{~b}$ shows that the mean $H / V$ ratios of the coda waves achieve a larger peak at longer period, and the difference between the $H / V$ ratios for the mainshock and aftershocks at short periods is not so strong as it was for the $\mathrm{S}$-waves, suggesting that the coda waves were mainly composed of the long-period surface waves. Considering these facts, the 1D S-wave velocity model depicted in Fig. $5 \mathrm{c}$ was constructed by trial and error to reproduce the peak period on the long-period side (1-10 s) of the $H / V$ spectral ratios for coda waves by utilizing the available geological and geophysical information discussed above. The material densities were estimated using the empirical relationship between the density and the
S-wave velocity obtained by Ludwig et al. (1970). The $\mathrm{S}$-wave velocities of the basin layers estimated in the present study are 200,350 , and $500 \mathrm{~m} / \mathrm{s}$ from surface to underlying hard rock, respectively; the thicknesses of the corresponding layers are 30, 200, and $240 \mathrm{~m}$, respectively (see Fig. 5c). The theoretical $H / V$ ratios for fundamental-mode Rayleigh waves and amplification factors for vertical incident plane $\mathrm{SH}$-waves for the new velocity model are shown in Fig. $5 \mathrm{~d}$, e, respectively; the corresponding values from Pandey (2000) are plotted in the same graphs for comparison. The structure proposed by Pandey (2000) achieves peak amplification at a period of approximately $2 \mathrm{~s}$, which is not supported by the observed ground-motion data, whereas the structure proposed in this study achieves a peak amplification 
period of approximately $4.0 \mathrm{~s}$, which corresponds to the peak response periods of the large-magnitude events, as shown in Fig. 4. A plot of the ratios of the $5 \%$ critically damped PSVRS at KATNP to those at KKN4 and those at NAST to those at KKN4 (see Additional file 2) shows that the peak response ratios at periods of approximately 4 and $1.5 \mathrm{~s}$ correspond well to the peak amplification periods depicted in Fig. 5e. The results also indicate that the velocity structure at the NAST site may be similar to that at the KATNP site.

As a preliminary validation of the proposed velocity model for long-period ground-motion simulations, we simulated velocity waveforms assuming a plane $\mathrm{SH}$ wave incidence at the base of the sediments. The transverse component of velocity records obtained by the differentiation of $5 \mathrm{~Hz}$ GPS displacement data obtained at the KKN4 site, which is a hard rock site, was used as input motion after halving the amplitudes to cancel the free surface effect. Because information on the damping factor Qs of the sediments in the Kathmandu basin is not available, we assumed a frequency-independent Qs equal to one-tenth of the S-wave velocity (unit: $\mathrm{m} / \mathrm{s}$ ) for each layer. It was found that the results discussed below were not significantly altered if the variation in Qs remained within a factor of two.

Figure 6 compares the observed and simulated velocity waveforms in the passband of $2-10 \mathrm{~s}$ for two different incident angles at the KATNP and NAST sites. In general, the new model was found to very well describe the observed S-wave amplitudes and S-waveforms at incidence angles in the range of $50^{\circ}-60^{\circ}$ at both basin sites, whereas the model proposed by Pandey (2000) was unable to reproduce the amplitudes and waveforms. The incidence angles also correspond to the location of the maximum slip deduced by Kubo et al. (2016). The above comparisons between the observations and simulations support the hypothesis that the deep sediments beneath the recording station played a significant role in the amplification of long-period (3-5 s) seismic waves in the Kathmandu basin. Kubo et al. (2016) showed that the amplitudes and waveforms for the S-waves can be well reproduced using the $1 \mathrm{D}$ basin model proposed in this paper and the complex rupture model proposed in their paper, whereas the model in Pandey (2000) strongly underestimates the amplitudes of S-waves. A 3D velocity model is necessary to fully understand the long-period ground motions in the Kathmandu basin.

\section{Conclusions}

Strong ground motions from the Mw 7.8 Gorkha earthquake and its eight aftershocks recorded by a strongmotion seismograph at the KATNP site were analyzed to understand the characteristics of strong ground motions
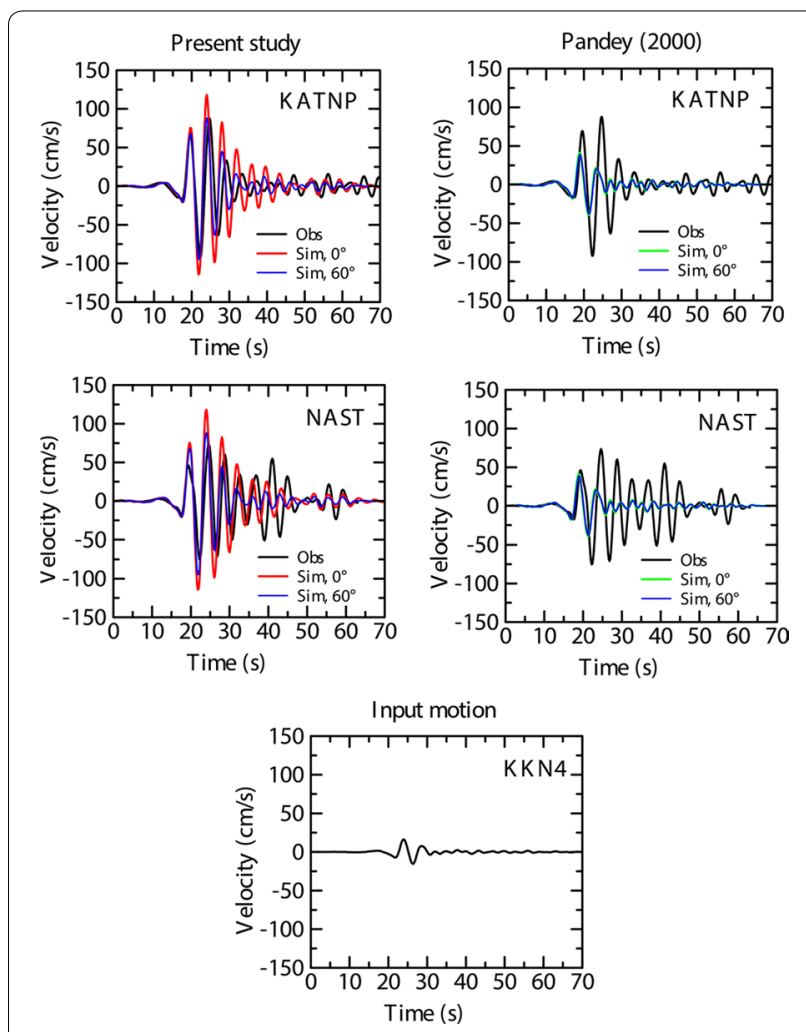

Fig. 6 Comparison of transverse components of observed and simulated waveforms $(0.1-0.5 \mathrm{~Hz})$

and site effects. The GMPEs developed for crustal and interplate events in Japan were found to generally well describe the observed PGAs and PGVs at the Kantipath site, except for the PGA of the mainshock. A comparison of the observed response spectra with those from the GMPEs indicated that the ground motions at the KATNP site were strongly influenced by the local site condition at long periods; hence, appropriate deep soil correction factors for the Kathmandu basin must be developed. An indirect analysis of the recordings for soil nonlinearity suggested that the KATNP site experienced a substantial reduction in short-period ground motions during the mainshock because of the nonlinear site response. To fully explain this nonlinearity, a broadband groundmotion simulation considering details regarding the surface soil layering, propagation path, and rupture characteristics of the earthquake is necessary. A $1 \mathrm{D}$ velocity structure model was developed for the deep sediments beneath the recording station based on the $H / V$ spectral ratios for the S-wave coda. A simple validation of the model by waveform simulations demonstrated that the proposed velocity model is able to explain the observed large-amplitude velocity waveforms at the peak periods of approximately $4-5 \mathrm{~s}$ for the mainshock. Thus, we 
conclude that the deep sediments beneath the recording station at the KATNP site strongly amplified the longperiod components of the ground motions during the mainshock and its large aftershocks.

\section{Additional files}

Additional file 1. Velocity seismograms of the mainshock at different passbands.

Additional file 2. Response ratios between the basin and rock sites for the mainshock.

\section{Authors' contributions}

YPD analyzed the strong ground-motion data, modeled the subsurface velocity model, interpreted the data, and drafted the manuscript. HK, WS, and TK interpreted the strong ground-motion data and edited the manuscript. SA and HF designed the study and edited the manuscript. All authors read and approved the final manuscript.

\section{Acknowledgements}

We thank the United States Geological Survey for providing us with strongmotion data and earthquake source locations. We also acknowledge the Department of Mines and Geology, Tribhuvan University, and the California Institute of Technology for providing us with the GPS data. We are grateful for the helpful comments given by two anonymous reviewers. We also would like to thank Wessel and Smith (1998) for providing us with Generic Mapping Tools, which were used to make Fig. 1 of this paper.

\section{Competing interests}

The authors declare that they have no competing interests.

Received: 2 November 2015 Accepted: 29 March 2016

Published online: 12 April 2016

\section{References}

Aguirre J, Irikura K (1997) Nonlinearity, liquefaction, and velocity variation of soft soil layers in Port Island, Kobe, during the Hyogo-ken Nanbu earthquake. Bull Seismol Soc Am 87:1244-1258

Atkinson GM, Boore DM (2003) Empirical ground-motion relations for subduction-zone earthquakes and their application to Cascadia and other regions. Bull Seismol Soc Am 93:1703-1729

Avouac JP, Meng L, Wei S, Wang T, Ampuero JP (2015) Lower edge of locked Main Himalayan Thrust unzipped by the 2015 Gorkha earthquake. Nat Geosci 8:708-711

Bhattarai M, Adhikari LB, Gautam UP, Laurendeau A, Labonne C, HosteColomer R, Sèbe O, Hernandez B (2015) Overview of the large 25 April 2015 Gorkha, Nepal, earthquake from accelerometric perspectives. Seismol Res Lett 86:1540-1548

Bird P (2003) An updated digital model of plate boundaries. Geochem Geophys Geosyst 4(3):1027

Boore DM, Joyner WB, Fumal TE (1997) Equation for estimating horizontal response spectra and peak acceleration from western north American earthquakes: a summary of recent work. Seismol Res Lett 68:128-153

CESMD (2015) Center for Engineering Strong Motion Data. http://strongmotioncenter.org/. Accessed 15 Sep 2015

Dhakal YP (2002) Study of P- \& S-waves and N-values in soft sediment of Kathmandu valley for their correlation and engineering significance. Master thesis, Tribhuvan University, p 141

Dhakal YP, Kubo H, Suzuki W, Kunugi T, Aoi S, Fujiwara H (2015) An analysis of the observed strong motion records at the Kantipath (KATNP) site during the 2015 Nepal earthquakes. Fall meeting, Seismological Society of Japan, S15-P02, p 202
Dhakal YP, Suzuki W, Kunugi T, Aoi S (2015b) Ground motion prediction equations for absolute velocity response spectra (1-10 s) in Japan for earthquake early warning. J Jpn Assoc Earthq Eng 15(6):91-111. doi:10.5610/ jaee.15.6_91

Dixit AM (1991) Geological effects and intensity distribution of the Udayapur (Nepal) earthquake of August 20, 1998. J Nepal Geol Soc 7(special issue): $1-17$

Dixit AM, Ringler AT, Sumy DF, Cochran ES, Hough SE, Martin SS, Gibbons S, Luetgert JH, Galetzka J, Shrestha SN, Rajaure S, McNamara DE (2015) Strong motion observations of the M 7.8 Gorkha, Nepal, earthquake sequence and development of the N-SHAKE strong-motion network. Seismol Res Lett 86:1533-1539

Galetzka JD, Melgar D, Genrich JF, Geng J, Owen S, Lindsey EO, Xu X, Bock Y, Avouac J-P, Adhikari LB, Upreti BN, Pratt-Sitaula B, Bhattarai TN, Sitaula BP, Moore A, Hudnut KW, Szeliga W, Normandeau J, Fend M, Flouzat M, Bollinger L, Shrestha P, Koirala B, Gautam U, Bhatterai M, Gupta R, Kandel T, Timsina C, Sapkota SN, Rajaure S, Maharjan N (2015) Slip pulse and resonance of Kathmandu basin during the 2015 Mw 7.8 Gorkha earthquake, Nepal imaged with geodesy. Science 349(6252):1091-1095

Ghimire S, Kasahara M (2007) Source process of the Ms =6.6, Udayapur earthquake of Nepal-India border and its tectonic implication. J Asian Earth Sci 31:128-138

Goda K, Kiyota T, Pokhrel RM, Chiaro G, Katagiri T, Sharma K, Wilkinson S (2015) The 2015 Gorkha Nepal earthquake: insights from earthquake damage survey. Front Built Environ 1:8

Hashash YMA, Tiwari B, Moss RES, Asimaki D, Clahan KB, Kieffer DS, Dreger DS, Macdonald A, Madugo CM, Mason HB, Pehlivan M, Rayamajhi D, Acharya I, Adhikari B (2015) Geotechnical field reconnaissance: Gorkha (Nepal) earthquake of April 252015 and related shaking sequence. Geotechnical Extreme Event Reconnaissance, GEER Association Report No. GEER-040, Version 1.1, p 250

His Majesty's Government of Nepal (HMG) and United Nations Development Programme United nations Center for Human Settlements (UNDP/ UNCHS) (1994) Seismic hazard mapping and risk assessment for Nepal. p 238

Ide S, Baltay A, Beroza GC (2011) Shallow dynamic overshoot and energetic deep rupture in the 2011 Mw 9.0 Tohoku-Oki earthquake. Science 332:1426-1429

Japan International Cooperation Agency (JICA) and Ministry of Home affairs (MoHA) of HMG of Nepal (2002) The study on earthquake disaster mitigation in the Kathmandu valley Kingdom of Nepal. Final report, vol 3, Main report 2/2, Earthquake disaster assessment and data base system, p 76

J-SHIS (Japan Seismic Hazard Information Station) (2016) http://www.j-shis. bosai.go.jp/en/. Accessed 15 Feb 2016

Kagawa T, Sawada S, Iwasaki Y (1992) On the relationship between azimuth dependency of earthquake ground motion and deep basin structure beneath the Osaka plain. J Phys Earth 40:73-83

Kanno T, Narita A, Morikawa N, Fujiwara H, Fukushima Y (2006) A new attenuation relation for strong ground motion in Japan based on recorded data. Bull Seismol Soc Am 96:879-897

Kawashima K, Aizawa K, Takahashi K (1984) Attenuation of peak ground motion and absolute acceleration response spectra. In: Proceedings of the 8th world conference on earthquake engineering. San Francisco, California, USA, 21-28 July, 1984, vol 2, pp 257-264

Kobayashi T, Morishita Yu, Yarai H (2015) Detailed crustal deformation and fault rupture of the 2015 Gorkha earthquake, Nepal, revealed from ScanSARbased interferograms of ALOS-2. Earth, Planets and Space 67:201

Kubo H, Dhakal YP, Suzuki W, Kunugi T, Aoi S, Fujiwara H (2016) Estimation of the source process of the 2015 Gorkha, Nepal, earthquake and simulation of long-period ground motions in the Kathmandu basin using a onedimensional basin structure model. Earth Planets Space 68:16

Lay T, Kanamori H, Ammon CJ, Koper KD, Hutko AR, Ye L, Yue H, Rushing TM (2012) Depth-varying rupture properties of subduction zone megathrust faults. J Geophys Res 117:B04311

Lermo J, Chavez-Garcia FJ (1993) Site effect evaluation using spectral ratios with only one station. Bull Seismol Soc Am 83:1574-1594

Ludwig WJ, Nafe JE, Drake CL (1970) Seismic refraction. the sea, vol 4. In: Maxwell AE (ed). Wiley Interscience, New York, pp 53-84

Ministry of Home Affairs, Government of Nepal (2015) http://www.moha.gov. np/. Accessed 23 Sep 2015 
Moribayashi S, Maruo Y (1980) Basement topography of the Kathmandu valley, Nepal - an application of gravitational method to the survey of a tectonic basin in the Himalayas. J Jpn Soc Eng Geol 21(2):30-37

Morikawa N, Fujiwara H (2013) A new ground motion prediction equation for Japan applicable up to m9 mega-earthquake. J Disaster Res 8(5):878-888 Nakamura M (2013) Information on long-period ground motion of the Japan Meteorological Agency. In: Proceedings of the 10th international workshop on seismic microzonation and risk reduction, Tokyo, Japan, 25 September, 2013, paper ID12

Nath SK, Thingbaijam KKS (2011) Peak ground motion predictions in India: an appraisal for rock sites. J Seismol 15:295-315

Noguchi S, Sasatani T (2008) Quantification of degree of nonlinear site response. In: 14th world conference on earthquake engineering, Beijing, Paper no. 03-03-0049

Noguchi S, Sasatani T (2011) Nonlinear soil response and its effects on strong ground motions during the 2003 Miyagi-Oki intraslab earthquake. Zisin 63:165-187 (in Japanese with English abstract)

Open Topography (2015). http://www.opentopography.org/index.php. Accessed 8 Sep 2015

Pandey MR (2000) Ground response of Kathmandu valley on the basis of microtremors. In: Proceedings of the 12th world conference on earthquake engineering, Auckland, New Zealand, 30 Jan-4 Feb 2000, Paper no. 2106

Parajuli H, Kiyono J, Ono Y, Tsutsumiuchi T (2008) Design earthquake ground motions from probabilistic response spectra: case study of Nepal. J Jpn Assoc Earthq Eng 8(4):16-28

Paudyal YR, Yatabe R, Bhandary NP, Dahal RK (2013) Basement topography of the Kathmandu Basin using microtremor observation. J Asian Earth Sci 62:627-637

Piya BK (2004) Generation of a geological database for the liquefaction hazard assessment in Kathmandu valley. Master thesis, International Institute for Geo-Information Science and Earth Observation, Enschede, The Netherlands, p 141

Richter CF (1958) Elementary seismology. WH Freeman \& Co Inc, Sanfrancisco, $768 \mathrm{p}$
Sakai H (2001) Stratigraphic division and sedimentary facies of the Kathmandu basin group, Central Nepal. J Nepal Geol Soc 25(special issue):19-32

Sato R (1979) Theoretical basis on relationships between focal parameters and earthquake magnitude. J Phys Earth 27:353-372

Si H, Midorikawa S (1999) New attenuation relationships for peak ground acceleration and velocity considering effects of fault type and site condition. J Struct Constr Eng AIJ 523:63-70 (in Japanese with English abstract)

Si H, Midorikawa S (2000) New attenuation relations for peak ground acceleration and velocity considering effects of fault type and site condition. In: Proceedings of the 12th world conference on earthquake engineering, Auckland, New Zealand, 30 Jan-4 Feb 2000, Paper no. 0532

Takai N, Shigefuji M, Rajaure S, Bijukchhen S, Ichiyanagi M, Dhital MR, Sasatani T (2016) Strong ground motion in the Kathmandu Valley during the 2015 Gorkha, Nepal, earthquake. Earth Planets Space 68:10

Takemura M (1990) Magnitude-seismic moment relations for the shallow earthquakes in and around Japan. Zisin 43:257-265 (in Japanese with English abstract)

USGS Event Page (2015) M5.1-41 km WNW of Kirtipur, Nepal. http://earthquake.usgs.gov/earthquakes/eventpage/us2000299v. Accessed 20 Oct 2015

USGS (United States Geological Survey) M7.8-36 km E of Khudi, Nepal. http:// earthquake.usgs.gov/earthquakes/eventpage/us20002926\#scientific_ finitefault. Accessed 8 Oct 2015

Wen KL, Chang TM, Lin CM, Chiang HJ (2006) Identification of nonlinear site response using the $\mathrm{H} / \mathrm{V}$ spectral ratio method. Terr Atmos Ocean Sci 17(3):533-546

Wessel P, Smith WHF (1998) New improved version of the generic mapping tools released. EOS Trans AGU 79:p579

Yagi Y, Okuwaki R (2015) Integrated seismic source model of the 2015 Gorkha, Nepal, earthquake. Geophys Res Lett 42:6229-6235

Yoshida M, Igarashi Y (1984) Neogene to Quaternary lacustrine sediments in the Kathamandu valley, Nepal. J Nepal Geol Soc 4:73-100

\section{Submit your manuscript to a SpringerOpen ${ }^{\circ}$ journal and benefit from:}

- Convenient online submission

- Rigorous peer review

- Immediate publication on acceptance

- Open access: articles freely available online

- High visibility within the field

- Retaining the copyright to your article

Submit your next manuscript at $>$ springeropen.com 